\title{
Residency education in Coronavirus Disease 2019 (COVID-19) times: Experience of a Chilean Otolaryngology Program
}

\author{
Matias Alvarez ${ }^{1}$, Antonia Lagos ${ }^{2}$, Valeria Sepulveda ${ }^{3}$, Carla Napolitano ${ }^{3}$, and Claudia \\ Gonzalez $^{3}$ \\ ${ }^{1}$ Pontificia Universidad Catolica de Chile Facultad de Medicina \\ ${ }^{2}$ Pontificia Universidad Catolica de Chile \\ ${ }^{3}$ Pontificia Universidad Católica de Chile
}

May 8, 2020

\section{KEY POINTS}

- The COVID-19 pandemic has presented the Otolaryngology community with new challenges.

- Exposure to outpatient attention, endoscopic procedures and surgeries has been significantly reduced for residents worldwide.

- Our Otolaryngology residency program has implemented different measures to reduce residents' exposure to high-risk infection situations.

- Concomitant measures have been taken to increase simulation training, and up-to-date seminars and courses for residents.

- Adaptation and flexibility of regular training curricula are required in order to diminish the negative impact in residents' education.

Keywords : COVID-19, SARS-CoV-2, residents, residency education, otolaryngology.

\section{INTRODUCTION}

The outbreak of Coronavirus Disease 2019 (COVID-19), an acute respiratory illness caused by the Severe Acute Respiratory Syndrome Coronavirus 2 (SARS-CoV-2), has become a global pandemic. This disease emerged in December 2019 in Wuhan, China, and the virus was first identified in January 2020, proven to be transmitted through contact and droplets ${ }^{1}$. The pandemic has spread worldwide; up to May 5 th 2020, the World Health Organization (WHO) reported 3,517,345 cases, and 243.401 deaths $^{2}$.In Chile, the first COVID-19 case was confirmed on March 3rd 2020; up to May 5th 2020, the Chilean Health Ministry reported 22,016 cases, and 275 deaths $^{3}$.

The most frequently reported symptoms are fever, cough, malaise, dyspnea, anorexia, and myalgias. Other less common symptoms are odynophagia, nausea, diarrhea, headache, and abdominal pain, and in some cases it may even be asymptomatic ${ }^{1}$. Several cases of olfactory and gustatory dysfunction have been reported in association to SARS-CoV-2 infection, yet further studies are required to establish their prevalence and natural history ${ }^{1}$.

Otolaryngologists are at a high risk of SARS-CoV-2 infection, given the high viral loads reported in the upper respiratory tract ${ }^{4}$, which is the main area examined and manipulated in endoscopic procedures by the specialty, increasing the risk of viral aerosols generation and propagation ${ }^{5}$. Givi et a l. recommend that non-urgent appointments or endoscopic examinations of the upper airway mucosa should be postponed to limit the chance of SARS-CoV-2 infection in patients and healthcare professionals, as well as postponing 
elective procedures that can be safely delayed. They also recommend a proper and optimal use of personal protection elements (PPE), with appropriate doffing and elimination techniques ${ }^{5}$.

In response to the emerging challenges for the specialty, Vukkadala et al . suggest major changes in department activities, including reducing the number of residents on service, exclusion of residents in staff clinics and surgeries to reduce risk of exposure, and remote department meetings and resident education sessions ${ }^{6}$.

This article aims to show the implemented strategies in a Chilean Otolaryngology residency program to overcome the challenges presented by the COVID-19 pandemic in our specialty.

\section{MATERIAL AND METHODS}

\section{Study design and methodology}

Descriptive study of the implemented measures in a Chilean Otolaryngology residency program in order to reduce the impact on the residents education. The measures include hands-on surgical teaching, in-patient care, outpatient care and in-person didactics.

\section{RESULTS}

We present the measures taken by a chilean Otolaryngology residency program, summarized in Table 1 .

\section{Daily Schedule and rotations}

The Universidad [Blinded for review] Residency is a 3-year program, currently including five residents per year, divided in four teaching hospitals in Santiago, Chile. In the COVID-19 pandemic, where limiting the exposure of healthcare professionals and maintaining the quality of attention to patients is the top priority, our Department implemented the following measures: optimal use of PPE according to aerosols generation risk; cancellation of all elective rotations outside the Otolaryngology Department; voluntary quarantine for residents with chronic pulmonary disease, pregnancy and immunosuppression; division of the available residents into "7 days on" and "14 days off" shift schedules, with everyday monitoring of respiratory symptoms appearance. Unfortunately, this resulted in a decrease of the overall procedures and surgeries performed by the residents over a month, as seen inTable 2 .

Finally, by the university's Postgraduate Committee order, all annual evaluations were suspended for at least 3 months.

\section{Surgical exposure and simulation}

Following the literature's recommendations ${ }^{5}$, all elective cases were suspended, and urgent or time dependent surgeries were only performed by attending Otolaryngologists. In order to deal with the absence of surgical exposure, during their "on" week, residents are expected to perform pre-established simulation training programs for nasal endoscopic surgery, and myringotomy with ventilation tubes placement. Other simulation training programs, such as microphonosurgery and septoplasty, are under development and validation, however, residents are expected to complete these courses as well.

\section{Didactics and Academics}

Keeping an up-to-date and continuous learning is fundamental for the Otolaryngology residency, and the COVID-19 pandemic has allowed alternative teaching methods to arise. For instance, all chilean first and second year Otolaryngology residents have mandatory unified core curriculum lessons twice a week between april and november, previously performed in-person by teachers from the Sociedad Chilena de Otorrinolaringología y Cirugía de Cabeza y Cuello. However, since the COVID-19 outbreak all the lectures and evaluations were changed to an online platform.

In the same way, our residency program introduced a dynamic academic schedule during the pandemia, hosted through a virtual platform: 
1.- Seminars regarding a topic of interest for residents are held twice a week, hosted by an assigned attending. The attending previously chooses bibliography for the seminar, where the topic is addressed and discussed according to the literature's clinical relevance and application.

2.- Every wednesday a Department meeting takes place, where a topic of interest is discussed and presented by a resident.

3.- The residents joined the "Collaborative Multi-Institutional Otolaryngology Residency Education Program", aiming to attend four conferences per week ${ }^{7}$.

4.- One module from Otosource was designated for each resident per week. The theme was decided according to the residency year ${ }^{8}$.

5.- The learning progress is objectified through formative pop quizzes once every two weeks using the CANVAS platform. These quizzes evaluate subjects addressed the previous week.

Finally, residents were encouraged to complete all the ongoing research, and create new retrospective studies during their "Off period".

Residents wellness

The current pandemia can be challenging for personal wellbeing, considering conditions of self isolation, anxiety about the future, and concern about personal and loved ones health. In order to cope with these problems a virtual reunion is held once a week, only for residents, to discuss the pandemia's impact on residents, and assess the need for schedule adjustments, and peer or professional support.

\section{DISCUSSION}

The Otolaryngology residency program is facing many challenges due to the suspension of the elective clinical procedures and surgeries in light of the high risk of infection, affecting the residents participation in the OR. In this descriptive study we present the report of an Otolaryngology residency program adapting to the ongoing pandemia.

This topic is also addressed by Crosbyet al. where the impact of SARS-CoV2 on American Otolaryngology residency programs is analyzed in terms of the expected decline in overall experience and accomplishment of the minimum key indicators established by the Accreditation Council for Graduate Medical Education. This especially affects residents coursing the last two years of their program. Other subjects are also discussed, particularly the implementation of online consortia didactic sessions, changes in the American Board of otolaryngology requirements, and the flexibility requested from supervision organizations ${ }^{9}$. Moreover, Comeret al. discusses how COVID-19 induced limitations have affected Otolaryngology training, and as a result three consortia have been developed in Otolaryngology residency education, including the "Collaborative Multi-Institutional Otolaryngology Residency Education Program". They also mention the possible need of at-home simulation models depending on the quarantine's duration ${ }^{10}$.

The COVID-19 pandemic is now affecting most residency programs, but specifically the Otolaryngology program due to the risks involved in upper-airway manipulation. There is no knowledge on how long the pandemic will last and how deeply it will affect the current resident cohort. We believe that adapting the program and keeping a close follow-up on indicators regarding residents participation in outpatient practice, procedures, and surgeries should be addressed in the future so we can design a further personalized reinforcement resident to resident. At the moment our program is considering as future options: rural surgical operatives to increase the number of surgeries performed by residents, case by case extension of the formative period, among others.

\section{CONCLUSIONS}

The SARS-CoV2 pandemia represents a novel and important challenge for the Otolaryngology residency education. Adaptation and flexibility of the regular training curricula are required in order to diminish the negative impact on residents' education. We describe the experience of a Chilean Otolaryngology program 
facing the impact of COVID-19, that may be useful for other programs during this pandemic, or in the event of future pandemics, natural disasters or wars.

\section{REFERENCES}

1. Krajewska J, Krajewski W, Zub K, Zatoński T. COVID-19 in otolaryngologist practice: a review of current knowledge. EurArchOtorhinolaryngol. 2020. doi:10.1007/s00405-020-05968-y

2. World Health Organization. Coronavirus disease 2019 (COVID-19) Situation Report - 106. WHO.https://www.who.int/emergencies/diseases/novel-coronavirus-2019/situation-reports/Accessed May 52020

3. Ministerio de Salud de Chile. Casos confirmados en Chile COVID-19. MINSALhttps://www.minsal.cl/nuevo-coronavirus-2019-ncov/casos-confirmados-en-chile-covid19/Accessed May 52020

4. Zou L, Ruan F, Huang M, et al. SARS-CoV-2 viral load in upper respiratory specimens of infected patients. New EnglandJournal of Medicine. 2020. 382(12), 1177-1179

5. Givi B, Schiff BA, Chinn SB, et al. Safety Recommendations for Evaluation and Surgery of the Head and Neck During the COVID-19 Pandemic. JAMA Otolaryngol Head NeckSurg. 2020. doi:10.1001/jamaoto.2020.0780

6. Vukkadala N, Qian ZJ, Holsinger FC, Patel, ZM, Rosenthal E. COVID-19 and the otolaryngologistpreliminary evidence-based review. TheLaryngoscope. 2020

7. Oghalai J. Collaborative multi-institutional otolaryngology residency education program. https://sites.usc.edu/ohnscovid/. AccessedMay 52020

8. OTOsource, American Academy of Otolaryngology Head and Neck Surgery Foundation.https://www.otosource.org/AccessedMay 52020

9. Crosby DL, Sharma A. Insights on Otolaryngology Residency Training during the COVID-19 Pandemic. Otolaryngology-Head and NeckSurgery. 2020

10. Comer BT, Gupta N, Mowry SE, Malekzadeh S. Otolaryngology Education in the Setting of COVID-19: Current and Future Implications. Otolaryngology-Head and NeckSurgery. 2020

\section{Hosted file}

Table 1 .docx available at https://authorea.com/users/319565/articles/449289-residencyeducation-in-coronavirus-disease-2019-covid-19-times-experience-of-a-chileanotolaryngology-program

\section{Hosted file}

Table 2.docx available at https://authorea.com/users/319565/articles/449289-residencyeducation-in-coronavirus-disease-2019-covid-19-times-experience-of-a-chileanotolaryngology-program 